\title{
Blueprint for Neuroscience
}

National Cancer Institute

\section{Source}

National Cancer Institute. Blueprint for Neuroscience. NCI Thesaurus. Code C82626.

A framework to enhance cooperative activities among the National Institutes of Health (NIH) Office of the Director and the NIH institutes and centers that support research on the nervous system. By pooling resources and expertise, the Blueprint takes advantage of economies of scale, confronts challenges too large for any single institute or center, and develops research tools and infrastructure that serve the entire neuroscience community. 